Original Article

\title{
DEVELOPMENT AND IN VIVO EVALUATION OF GASTRORETENTIVE FLOATING TABLETS OF ANTIPSYCHOTIC DRUG RISPERIDONE
}

\author{
A. KISHORE BABU ${ }^{* 1,2}$, M. V. RAMANA ${ }^{1}$
}

1G. B. N. Institute of Pharmacy, Edulabad, Ghatkesar, R. R. Dist 501301, Telangana, India, ${ }^{2}$ Jawaharlal Nehru Technological University, Kukatpally, Hyderabad 500072, Telangana, India

Email: akishorebabu@gmail.com

Received: 05 Nov 2015 Revised and Accepted: 09 Sep 2016

\begin{abstract}
Objective: The objective of this research work was to formulate and evaluate the floating drug delivery system containing Risperidone, to improve oral bioavailability by increasing gastric residence time.

Methods: Total fifteen formulations of Risperidone floating tablets were prepared by direct compression method using different grades of HPMC polymers, Gelucire, Polyox and $\mathrm{NaHCO}_{3}$. In vivo radiographic studies were performed in human volunteers by incorporating barium sulphate.

Results: The prepared tablets were characterized and found to exhibit satisfactory physicochemical characteristics. All the prepared batches showed good in vitro buoyancy with low floating lag time. It was observed that the tablets remained buoyant for more than $12 \mathrm{~h}$. Optimized formulation (F15) consisting of HPMC K100M, WSR 301, Gelucire 50/13 and $\mathrm{NaHCO}_{3}$, followed diffusion controlled zero-order kinetics and nonfickian transport of the drug. FTIR and DSC studies revealed the absence of any chemical interaction between drug and polymers used. The in vivo radiographic studies revealed that the tablets remained in the stomach for $6 \mathrm{~h}$ in fasting human volunteers. In vivo bioavailability studies performed in healthy human volunteers and $\mathrm{T}_{\max }, \mathrm{C}_{\max }$, AUC was calculated and confirmed significant improvement in bioavailability when compared with marketed formulation Respidon 2.
\end{abstract}

Conclusion: The data obtained thus suggests that floating delivery system of Risperidone can be successfully designed to give controlled drug delivery and improved oral bioavailability.

Keywords: Risperidone, HPMC, Gelucire, X-ray radiographic studies, In vivo bioavailability studies

(C) 2016 The Authors. Published by Innovare Academic Sciences Pvt Ltd. This is an open access article under the CC BY license (http://creativecommons. org/licenses/by/4. 0/) DOI: http://dx.doi.org/10.22159/ijpps.2016v8i11.9810

\section{INTRODUCTION}

The importance of controlled drug delivery systems that release the drug over an extended period of time has long been recognized in the pharmaceutical field. Application of such controlled release technology to oral drug delivery system, however, has been limited because the actual time for effective drug delivery is restricted by gastrointestinal transit time [1].

Bioadhesive systems work by adhering to the gastric epithelial cell surface or mucin using bioadhesive polymers [2]. Drugs with short half-lives are eliminated quickly. Therefore frequent dosing is required to maintain the therapeutic activity. To release the drug in a sustained and slow manner, GRDDS formulations are one strategy [3]. GRDDS have relative low gastric emptying time (GET) of drugs in the human gut, the major site of absorption which averages $2-3 \mathrm{~h}$, this low dwell time of drugs in upper regions of GI tract results in incomplete drug absorption which leads to reduced efficiency of the dosage form [4]. To improve the continuous available of the drug to the absorption site hydrophilic polymers are used to make the dosage form float in the stomach for the longer duration [5].

However, the issue in the development of oral controlled release dosage forms is to prolong the residence time of dosage forms in the stomach or upper gastrointestinal (GI) tract until the drug is completely released [6]. Rapid GI transit could result in incomplete drug release from the drug delivery device in the absorption zone leading to the diminished efficacy of the administered dose [7]. The principle of buoyant preparation offers a simple and practical approach to achieve increased residence time for the dosage form in the stomach and sustained drug release. In the present study HPMC K4, HPMC K15 and HPMC K100M, HPMC E15 were used since it is reported that it swells to a great extent and forms a stronger gel that is less prone to erosion. The rate of drug release from the hydrophilic matrix is dependent on various factors such as types of polymer, the solubility of drug, polymer content, the particle size of drug and polymer as well as types and amount of filler used in the formulation [8]. The adjustment of polymer concentration, viscosity grade and the addition of different types and levels of excipients to the polymer matrix can modify the kinetics of drug release [9]. Risperidone, a second-generation antipsychotic drug, is widely used in the clinical management of schizophrenia, bipolar and irritability disorders. Risperidone lipophilic in nature is rapidly and completely absorbed orally and extensively metabolized by cytochrome P450 2D6 into a major metabolite 9-Hydroxy-risperidone. 9-Hydroxyrisperidone is pharmacological as much potential as that of the parent compound [10]. Risperidone has an elimination half-life of $3 \mathrm{~h}$ in extensive metabolizers and $17 \mathrm{~h}$ in poor and extensive metabolizers [11]. Therefore, gastric and intestinal transient times have a significant effect on the rate and extent of oral absorption of the drug. As a result, variable oral bioavailability may be expected. Investigations were performed to see the effect of floating agent content and Risperidone content upon the floating lag time of the tablets. The impact of formulation variables upon the release rate, mean dissolution time and release mechanism was also evaluated with the help of various mathematical models. Risperidone has absorption window in upper G. I. tract, and due to this often display low bioavailability [12]. The aim of the present study was to prepare and characterize sustained release floating matrix tablets of Risperidone using Gelucire44/14, WSR 301, WSR N10, HPMC K4, HPMC K15 and HPMC K100M, HPMC E15.

\section{MATERIALS AND METHODS}

\section{Materials}

RESPIDON-2 tablet was purchased from Torrent Pharmaceuticals Ltd, Mumbai. Risperidone was generous gift sample from Dr. Reddy's Laboratories Ltd, Hyderabad. Hydroxy propyl methyl cellulose $\mathrm{K}-15 \mathrm{M}$ and $\mathrm{K}-100 \mathrm{M}$ were obtained from Rubicon labs, Mumbai, India, POLYOX WSR 301 and N10 was obtained from Dow 
Chemical's, New York. Gelucire 44/14, Gelucire 50/13 and PVP K 30 were gifted from MSN Labs Ltd, Hyderabad. All other excipients and chemicals used were of analytical grade.

\section{Methods}

\section{Preparation of risperidone floating tablet}

The tablets were prepared by direct compression method [13]. All the ingredients except Risperidone were passed through \#85 mesh prior to mixing. The ingredients were weighed separately and mixed to get a uniform polymer mixture. The drug was then mixed with the polymer mixtures were lubricated with magnesium state and talc was compressed to obtain tablets.

\section{Formulation development}

Hydrophilic polymer matrix systems were widely used in oral controlled drug delivery because of their flexibility to obtain a desirable drug release profile, cost effectiveness, and broad regulatory acceptance.

Present study aims in design of sustained release floating formulations of Risperidone using hydrophilic polymers to control the drug release and a lipid excipient to decrease the gastric irritation and to enhance the penetration of drug formulations are developed using Gelucire 44/14, Gelucire 50/13, WSR 301, WSR N10, HPMC K4, HPMC K15 and HPMC K100M, HPMC E15 etc.

Table 1: Formulation composition of floating tablets

\begin{tabular}{|c|c|c|c|c|c|c|c|c|c|c|}
\hline Formulations & $\begin{array}{l}\text { Risperidone } \\
\text { (mg) }\end{array}$ & $\begin{array}{l}\text { HPMC } \\
\text { K4M } \\
\text { (mg) }\end{array}$ & $\begin{array}{l}\text { HPMC } \\
\text { K15M } \\
\text { (mg) }\end{array}$ & $\begin{array}{l}\text { HPMC } \\
\text { K100M } \\
\text { (mg) }\end{array}$ & $\begin{array}{l}\text { HPMC } \\
\text { E15 } \\
\text { (mg) }\end{array}$ & $\begin{array}{l}\text { WSR } \\
\text { N10 } \\
\text { (mg) }\end{array}$ & $\begin{array}{l}\text { WSR } \\
301\end{array}$ & $\begin{array}{l}\mathrm{NAHCO}_{3} \\
\text { (mg) }\end{array}$ & $\begin{array}{l}\text { Gelucire } \\
44 / 14 \\
(\mathrm{mg})\end{array}$ & $\begin{array}{l}\text { Gelucire } \\
50 / 13 \\
(\mathrm{mg})\end{array}$ \\
\hline F1 & 2 & 20 & - & - & - & 30 & - & 20 & - & 26 \\
\hline $\mathrm{F} 2$ & 2 & 22.5 & - & - & - & - & 30 & 25 & - & 18.5 \\
\hline F3 & 2 & 25 & - & - & - & - & 25 & 26 & 20 & - \\
\hline $\mathrm{F} 4$ & 2 & 27.5 & - & - & 13.5 & 15 & - & 30 & 10 & - \\
\hline F5 & 2 & 30 & - & - & - & 20 & - & 36 & - & 10 \\
\hline F6 & 2 & & 20 & - & - & - & 30 & 20 & 26 & - \\
\hline F7 & 2 & - & 22.5 & - & - & 18.5 & - & 25 & - & 30 \\
\hline F8 & 2 & - & 25 & - & - & 30 & - & 25 & - & 16 \\
\hline F9 & 2 & - & 27.5 & - & 20 & - & - & 30 & 18.5 & - \\
\hline F10 & 2 & - & 30 & - & 15 & 16 & - & 35 & - & - \\
\hline F11 & 2 & - & & 20 & - & - & 30 & 30 & 16 & - \\
\hline F12 & 2 & - & & 22.5 & - & - & 25.5 & 38 & 10 & - \\
\hline F13 & 2 & - & - & 25 & - & - & 15 & 40 & - & 16 \\
\hline F14 & 2 & - & - & 27.5 & 12.5 & 14 & - & 42 & - & - \\
\hline F15 & 2 & - & - & 30 & - & - & 11 & 45 & - & 10 \\
\hline
\end{tabular}

NOTE: Each formulation contains $1 \%$ magnesium stearate and $1 \%$ talc. Total tablet weight $100 \mathrm{mg}$.

\section{Evaluation of floating tablets [14]}

\section{a) Thickness}

The thickness of the prepared tablets was tested using vernier calipers. The test was done in triplicate and average was determined.

\section{b) Hardness}

The hardness of prepared tablets was determined using Monsanto hardness tester and measured in terms of $\mathrm{kg} / \mathrm{cm}^{2}$.

\section{c) Weight variation}

The weight variation test was performed as per the I. P. guidelines. Twenty randomly taken tablets were weighed together and the average weight was determined. Each tablet was then weighed individually and deviation from average weight was calculated.

\section{d) Friability}

A sample of twenty randomly selected tablets were accurately weighed and placed in a Roche friabilator. It was operated for $4 \mathrm{~min}$ at a speed of $25 \mathrm{rpm}$, and then the tablets were removed, de-dusted and reweighed. The percent loss in weight due to abrasion and impact was calculated as,

$$
\% \text { Friability= (Loss in weight/Initial weight) } \mathrm{x} 100 .
$$

\section{e) Drug content}

Ten tablets for each batch was taken and triturated. Powder equivalent to $100 \mathrm{mg}$ of drug was weighed and was transferred to breaker and $0.1 \mathrm{~N} \mathrm{HCl}$ was added and it was then shaken for $5 \mathrm{~min}$ and finally $0.1 \mathrm{~N} \mathrm{HCl}$ was added to make the volume up to $100 \mathrm{ml}$ and solution was then sonicated for $15 \mathrm{~min}$ and filtered through Whatman filter paper. Finally, a solution was diluted suitably and the absorbance of the resultant solution was measured to determine the drug content spectrophotometrically at $241 \mathrm{~nm}$ using UV/Visible spectrophotometer Shimadzu 1800 against $0.1 \mathrm{~N} \mathrm{HCl} \mathrm{blank.}$

\section{f) Swelling studies}

The extent of swelling was measured in terms of \% of weight gained by the tablet. One tablet from each formulation was weighed and kept in a petri dish containing $50 \mathrm{ml}$ of $0.1 \mathrm{~N} \mathrm{HCl}$ buffer solution. At the end of specified time, intervals tablets were withdrawn from petri dish and excess buffer blotted with tissue paper and weighed. The \% of weight gained by the tablet was calculated by using the following formula:

$$
\text { Swelling Index (\%) = Mt-Mo } / M_{0} X 100 \text { [15]. }
$$

\section{Buoyancy lag time determination and total floating time}

The in vitro buoyancy was determined by the floating lag time. The tablet was placed in a $250 \mathrm{ml}$ beaker containing $0.1 \mathrm{~N} \mathrm{HCl}$. The time required for the tablet to rise to the surface for floating was determined as the buoyancy lag time and further total floating time of all tablets was determined by visual observation [16].

\section{In vitro dissolution studies}

In vitro drug release studies for the prepared immediate release, tablets were conducted for a period of $12 \mathrm{~h}$ using USP XXIV type-II (Paddle) dissolution apparatus at $37 \pm 0.5^{\circ} \mathrm{C}$ at $50 \mathrm{rpm}$ using $900 \mathrm{ml}$ of $0.1 \mathrm{~N} \mathrm{HCl}$ as dissolution medium. At a predetermined interval of time, $5 \mathrm{ml}$ of sample was withdrawn from the dissolution medium and replaced with fresh medium. After filtration and appropriate dilution, the samples were analyzed for cumulative percentage drug release of Risperidone by UV/Visible spectrophotometer Shimadzu 1800 at $241 \mathrm{~nm}$.

Wavelength: $241 \mathrm{~nm}$

\section{Kinetic modeling of drug release}

To analyze the mechanism of drug release from the tablets the in vitro dissolution data was fitted to zero order, first order, Higuchi and Korsmeyer-Peppas model. 


\section{Zero order equation}

This equation describes the systems where the release rate is independent of the concentration of the dissolved species. The dissolution data are fitted into zero order equation.

$$
\mathrm{Q}=\mathrm{Q}_{\mathrm{o}} \mathrm{K}_{\mathrm{o}} \mathrm{t} \text {, }
$$

\section{Where}

$\mathrm{Q}=$ Amount of drug released at time $\mathrm{t}$

$Q_{0}=$ Amount of drug release initially

$\mathrm{K}_{\mathrm{o}} \mathrm{t}=$ Zero order rate constant

A graph of concentration vs. time would yield a straight line with a slope equal to $\mathrm{K}_{\mathrm{o}}$ and the intercept at the origin of the axes. The zero order plot is derived from plotting the cumulative percent drug dissolved Vs time.

\section{First order Equation}

The first order equation describes the release from systems where dissolution rate is dependent upon the concentration of the dissolving species release behavior

Generally follows the following first order release equation.

$$
\text { In } \mathrm{M}=\mathrm{In} \mathrm{M} 0-\mathrm{K} 1 \mathrm{t}
$$

\section{Where}

$M$ is the amount of drug dissolved at time $t$,

$\mathrm{M} 0$ is the amount of drug dissolved at $\mathrm{t}=0$ and

M1 is the first order rate constant.

A graph of log concentration of drug release Vs time yields line.

\section{Higuchi Square Root law}

A form of the Higuchi Square Root Law is given by equation

$$
\mathrm{Q}=\mathrm{KS} \sqrt{\mathrm{t}}
$$

Where

$\mathrm{Q}=$ Amount of drug dissolved at time $\mathrm{t}$,

Ks=Higuchi rate constant

The Higuchi square root law equation describes the release from a system where the solid drug is dispersed in an insoluble matrix, and the rate of drug release is related to the rate of drug diffusion.

\section{Korsmeyer and Peppas release model}

The release rate data were fitted to the following equation

$$
\mathrm{Mt} / \mathrm{M} \alpha=\mathrm{K} \cdot \mathrm{t}^{\mathrm{n}}
$$

Where

$\mathrm{Mt} / \mathrm{M} \alpha=$ the fraction of drug released,

$\mathrm{K}=$ the release constant $\mathrm{t}^{\prime}$ ' is the release time.

' $\mathrm{n}$ ' is diffusion exponent, if $\mathrm{n}$ is equal to 0.89 , the release is Zero order. If $\mathrm{n}$ is equal to 0.45 the release is best explained by Fukien diffusion, and if $0.45<\mathrm{n}<0.89$ then the release is through anomalous diffusion or nonfickian diffusions (Swellable and Cylindrical Matrix)

In this model, a plot of $\log (\mathrm{Mt} / \mathrm{M} \alpha)$ vs. $\log$ time was plotted, and the slope was noted to explain release pattern.

\section{Drug excipient compatibility studies}

\section{Fourier transform infrared spectroscopy (FTIR)}

FTIR spectra for the pure drug, physical mixture and optimized formulations were recorded using a Fourier transform Infrared spectrophotometer. The analysis was carried out in Shimadzu-IR Affinity 1 Spectrophotometer. The IR spectrum of the samples was prepared using $\mathrm{KBr}$ (spectroscopic grade) disks by means of hydraulic pellet press at a pressure of seven to ten tons.

\section{Differential scanning calorimetry (DSC)}

Differential Scanning Calorimetry (DSC) studies were carried out using DSC 60, having TA60 software, Shimadzu, Japan. Accurately weighed samples were placed on the aluminum plate, sealed with aluminum lids and heated at a constant rate of $5{ }^{\circ} \mathrm{C} / \mathrm{min}$, over a temperature range of 0 to $250{ }^{\circ} \mathrm{C}$.

\section{Stability studies}

The stability studies were carried out as per ICH guidelines. The best formulation F15 was subjected to accelerated stability test by storing at $40 \pm 2{ }^{\circ} \mathrm{C} / 75 \pm 5 \%$ relative humidity in an accelerated stability chamber (Remi, Mumbai). After specified period of time (1, 2 and 3 months) samples were withdrawn and floating lag time, total floating time and in vitro dissolution studies were conducted [17]

\section{Radiographic studies}

The radiographic and In vivo bioavailability study protocol of Risperidone floating tablets was approved by the Institutional Human Ethics Committee (IHEC), bearing No: IHEC/VGOPC/ 051/2015, Vaagdevi Group of Pharmacy Colleges, Warangal, India.

\section{Determination of In vivo gastric residence time}

For this study, the tablets are prepared by replacing half the amount of drug with barium sulfate. After overnight fasting, the volunteers were fed with a low-calorie food. After half an hour, a barium sulfate-labeled tablet was given to every subject with $200 \mathrm{ml}$ of water. The volunteers were asked to take $200 \mathrm{ml}$ water after every $1 \mathrm{~h}$. At different time intervals $(0.5,2,4$, and $6 \mathrm{~h}$ post administration of tablets), the volunteers were exposed to abdominal X-ray imaging in standing position. The distance between the source of X-rays and the subject was kept constant for all images. Thus, the observation of the floating tablet movements could be easily noticed. The mean gastric retention period was estimated.

\section{In vivo bioavailability studies}

\section{In vivo study protocol [18]}

Twelve healthy male subjects with a mean age of $28.83 \pm 3.60$ y (ranging from 24 to $34 \mathrm{y}$ ), mean weight $69.33 \pm 7.61 \mathrm{Kg}$ (ranging from 61 to $79 \mathrm{Kg}$ ) and a mean height of $173.17 \pm 10.46 \mathrm{~cm}$ (ranging from 157 to $182 \mathrm{~cm}$ ) participated in this study. Informed and signed consent and approval of the Human Ethical Committee were obtained. The volunteers were judged healthy on the basis of their previous medical history, physical examination and routine laboratory tests. None of the subjects used alcohol or tobacco. All subjects were free from drugs $15 \mathrm{~d}$ before and during the study. They were randomly divided into 2 groups of 6 subjects each. The subjects were fasted overnight at least $10 \mathrm{~h}$ prior to dose. After collecting the zero hour blood sample (blank). A high standardized fat breakfast approximately $900 \mathrm{KCal}$ was given in the morning halfan-hour before administration. Group A received Formulated Risperidone and group B received commercial formulation was administered with $200 \mathrm{ml}$ of water. All the subjects were given a glass of water for every $2 \mathrm{~h}$ (approximately $200 \mathrm{ml}$ ). Standardized lunch, snacks and dinner were provided to all the subjects respectively at 4,8 and $12 \mathrm{~h}$ after the administration of formulations. Blood samples $(2 \mathrm{ml})$ were collected by the intravenous route using heparinized disposable syringes at the following times: $0.5,1,1.5,2$, $2.5,3,4,6,8,12,20$ and $24 \mathrm{~h}$. The blood samples were collected in vacutainers containing EDTA as an anticoagulant and immediately centrifuged at $3000 \mathrm{rpm}$ for $15 \mathrm{~min}$. The separated plasma samples were stored at-200C until analyzed.

Determination of risperidone in human plasma by HPLC method

Determination of Risperidone using internal standard trihexyphenidyl hydrochloride by high performance liquid chromatography with a RP-C18 chromatographic column, Phenomenex Kinetex $(150 \mathrm{~mm} \times 4.6 \mathrm{~mm}$ i. d) and a mobile phase consisting of methanol: acetonitrile: $0.05 \mathrm{M}$ phosphate buffer $(\mathrm{pH}$ $3.7)(60: 30: 10, \mathrm{v} / \mathrm{v} / \mathrm{v})$ at a flow rate $1.0 \mathrm{ml} / \mathrm{min}$ and the wavelength 
detection was $230 \mathrm{~nm}$. The retention time for Risperidone and internal standard trihexyphenidyl hydrochloride was $3.797 \mathrm{~min}$ and 5.389 min respectively [19].

\section{Preparation of plasma samples for HPLC analysis}

Human plasma $(0.5 \mathrm{ml})$ was prepared for chromatography by precipitating proteins with $2.5 \mathrm{ml}$ of ice-cold absolute ethanol for each $0.5 \mathrm{ml}$ of plasma. After centrifugation, the ethanol was transferred into a clean tube. The precipitate was resuspended with $1 \mathrm{ml}$ of acetonitrile by vortexing for $1 \mathrm{~min}$. After centrifugation (5000-6000 rpm for $10 \mathrm{~min}$ ), the acetonitrile was added to the ethanol and the organic mixture was taken to near dryness by a steam of nitrogen at room temperature. Samples were reconstituted in $200 \mu 1$ of $50 \%$ of acetonitrile and $50 \%$ methanol was injected for HPLC analysis.

\section{Pharmacokinetic analysis}

The pharmacokinetic parameters, peak plasma concentrations $\left(\mathrm{C}_{\max }\right)$ and time to reach peak concentration $\left(t_{\max }\right)$ were directly obtained from concentration-time data. In the present study, $\mathrm{AUC}_{0-\mathrm{t}}$ refers to the AUC from 0 to $24 \mathrm{~h}$, which was determined by linear trapezoidal rule and $\mathrm{AUC}_{0-\alpha}$ refers to the AUC from time at zero hours to infinity.

The AUC $_{0-\alpha}$ was calculated using the formula $\mathrm{AUC}_{0-\mathrm{t}}+\left[\mathrm{C}_{\text {last }} / \mathrm{K}\right]$ where $\mathrm{C}$ last is the concentration in $\mu \mathrm{g} / \mathrm{ml}$ at the last time point and $\mathrm{K}$ is the elimination rate constant.

Various pharmacokinetic parameters like the area under the curve [AUC], elimination half-life $\left(t_{1} / 2\right)$. The volume of distribution $\left(V_{d}\right)$, total clearance $\left(\mathrm{Cl}_{\mathrm{T}}\right)$ and mean residence time for each subject using a non-compartmental pharmacokinetic program. The pharmacokinetic parameters were performed by a noncompartmental analysis using Win Nonlin $3.3 \AA$ pharmacokinetic software (Pharsight Mountain View, CA USA). All values are expressed as the mean \pm SD. Statistical analysis was performed with Graph Pad InStat software (version 3.00, Graph Pad Software, San Diego, CA, USA) using one-way analysis of variance (ANOVA) followed by Tukey-Kramer multiple comparison test. The difference with $\mathrm{p}<0.05$ was considered statistically significant.

\section{RESULTS AND DISCUSSION}

Evaluation of physicochemical parameters

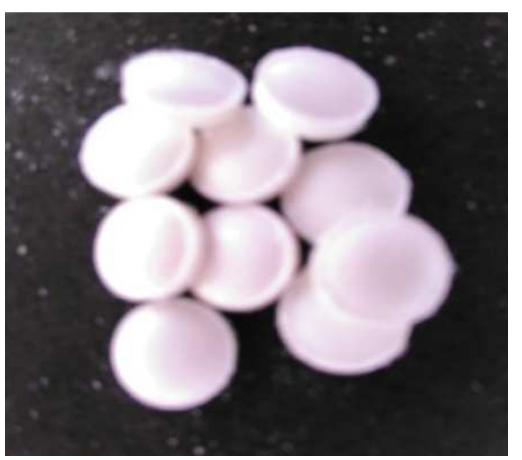

Fig. 1: Risperidone floating tablets

Table 2: Physico-chemical parameters of Risperidone floating tablets

\begin{tabular}{|c|c|c|c|c|}
\hline Formula code & Hardness $\left(\mathrm{Kg} / \mathrm{cm}^{2}\right)$ & Thickness (mm) & (\%) Friability & Uniformity of Weight (mg) \\
\hline F1 & $2.4 \pm 0.12$ & $2.39 \pm 0.02$ & $0.55 \pm 0.01$ & $95 \pm 1.6$ \\
\hline $\mathrm{F} 2$ & $2.6 \pm 0.16$ & $2.38 \pm 0.01$ & $0.53 \pm 0.04$ & $95 \pm 1.3$ \\
\hline F3 & $2.3 \pm 0.21$ & $2.38 \pm 0.03$ & $0.66 \pm 0.02$ & $98 \pm 1.7$ \\
\hline F4 & $2.9 \pm 0.14$ & $2.37 \pm 0.01$ & $0.67 \pm 0.04$ & $95 \pm 2.4$ \\
\hline F5 & $2.8 \pm 0.19$ & $2.35 \pm 0.01$ & $0.75 \pm 0.05$ & $96 \pm 2.1$ \\
\hline F6 & $2.0 \pm 0.2$ & $2.36 \pm 0.02$ & $0.72 \pm 0.02$ & $97 \pm 2.2$ \\
\hline F7 & $2.2 \pm 0.8$ & $2.38 \pm 0.03$ & $0.70 \pm 0.01$ & $96 \pm 1.4$ \\
\hline F8 & $2.7 \pm 0.02$ & $2.39 \pm 0.03$ & $0.65 \pm 0.02$ & $97 \pm 1.5$ \\
\hline F9 & $2.6 \pm 0.8$ & $2.39 \pm 0.02$ & $0.66 \pm 0.01$ & $98 \pm 1.0$ \\
\hline F10 & $2.4 \pm 0.1$ & $2.39 \pm 0.03$ & $0.57 \pm 0.03$ & $96 \pm 1.2$ \\
\hline F11 & $2.5 \pm 0,1$ & $2.42 \pm 0.04$ & $0.52 \pm 0.02$ & $98 \pm 1.6$ \\
\hline F12 & $2.3 \pm 0.2$ & $2.46 \pm 0.03$ & $0.58 \pm 0.06$ & $95 \pm 2.0$ \\
\hline F13 & $2.4 \pm 0.3$ & $2.62 \pm 0.05$ & $0.61 \pm 0.04$ & $97 \pm 2.0$ \\
\hline F14 & $2.6 \pm 0.4$ & $2.39 \pm 0.05$ & $0.62 \pm 0.02$ & $98 \pm 1.9$ \\
\hline F15 & $2.5 \pm 0.5$ & $2.34 \pm 0.04$ & $0.64 \pm 0.04$ & $99 \pm 2.1$ \\
\hline
\end{tabular}

mean \pm SD $(n=3)$

Floating tablets of 15 different formulations of Risperidone were formulated by direct compression technique, using different polymers like HPMC K4, HPMC K15, HPMC K100, HPMC E15, Gelucire 50/13, Gelucire 44/14, WSR 301 and WSR N10. All the formulation was evaluated for their various physical parameters.

The prepared 15 different formulations of Risperidone were evaluated for physicochemical properties and the results are depicted in table 2 . The tablets were white, circular in shape and were found to be uniform with respect to weight variation (95 to 99 $\mathrm{mg}$ ) and hardness ( 2.3 to $2.7 \mathrm{~kg} / \mathrm{cm}^{2}$ ). The thickness $(2.34$ to 2.62 $\mathrm{mm})$ and friability ( 0.52 to $0.75 \%$ ) of different tablets were found within acceptable range.

Fifteen formulations were evaluated for in vitro buoyancy lag time and total floating period and drug content. The time required for the tablet to rise to the surface (when the tablets were placed in a beaker containing $0.1 \mathrm{~N} \mathrm{HCl}$ ) for floating was described as the buoyancy lag time. $\mathrm{NaHCO}_{3}$ induces $\mathrm{CO}_{2}$ generation in the presence of $\mathrm{HCl}$. All the formulations had buoyancy lag time in the range of 30 to $84 \mathrm{sec}$. The total floating period was found to be more than $12 \mathrm{~h}$, which indicates a stable gel layer formation by all polymers and that
$\mathrm{NaHCO}_{3}$ remains for a longer time. Drug content uniformity in all formulations was calculated and the percent of active ingredient ranged from 72 to $99 \%$. The results of floating lag time and total floating time was depicted in table 3.

\section{Study of swelling characteristics of risperidone floating tablets}

The percentage swelling obtained from the water uptake studies of formulations is shown in the table. The formulations with HPMC K4, HPMCK15 and HPMCK100, showed the swelling and tablet integrity. The change in sodium bicarbonate concentration did not show any effect on swelling of the tablet. The complete swelling was achieved at the end of $8 \mathrm{hr}$, then diffusion and erosion take place. The formulation containing K100 shows the higher swelling compared to that of the formulations containing $\mathrm{K} 15 \mathrm{M}$ and $\mathrm{K} 4 \mathrm{M}$. The swelling index of the tablets increases with an increase in the polymer viscosity grade

\section{In vitro drug release studies}

All the formulations (F1-F15) were prepared with polymers like HPMC with different grades, POLYOX WSR 301and N10 and lipid 
excipients Gelucire 44/14 and 50/13. The release of Risperidone from different formulations was carried out in $0.1 \mathrm{~N} \mathrm{HCl}$ and the results are depicted in Table. The highest drug release was found in the formulation F15 i.e. $99.45 \%$ within $12 \mathrm{~h}$ when compared with other formulations. F15 was found to be optimized formulation based on the dissolution and other evaluation parameters.

Table 3: In vitro floating ability and drug content of Risperidone floating tablets

\begin{tabular}{llll}
\hline Formula code & Buoyancy lag time* $(\mathbf{s e c})$ & Total floating period* & Drug content** (\%) \\
\hline F1 & 84 & $>12$ & $72 \pm 0.1$ \\
F2 & 80 & $>12$ & $85 \pm 0.1$ \\
F3 & 77 & $>12$ & $98 \pm 0.5$ \\
F4 & 74 & $>12$ & $83 \pm 0.2$ \\
F5 & 70 & $>12$ & $93 \pm 0.4$ \\
F6 & 68 & $>12$ & $78 \pm 0.2$ \\
F7 & 65 & $>12$ & $83 \pm 0.1$ \\
F8 & 61 & $>12$ & $96 \pm 0.3$ \\
F9 & 57 & $>12$ & $82 \pm 0.2$ \\
F10 & 54 & $>12$ & $91 \pm 0.1$ \\
F11 & 50 & $>12$ & $97 \pm 0.2$ \\
F12 & 45 & $>12$ & $95 \pm 0.5$ \\
F13 & 40 & $>12$ & $94 \pm 0.4$ \\
F14 & 36 & $>12$ & $87 \pm 0.2$ \\
F15 & 30 & $>12$ & $99 \pm 0.1$ \\
\hline
\end{tabular}

mean \pm SD $(n=3)$

Table 4: Cumulative \%drug release of formulations F1-F5

\begin{tabular}{|c|c|c|c|c|c|}
\hline Time (h) & F1 & F2 & F3 & F4 & F5 \\
\hline 0 & $0 \pm 0$ & $0 \pm 0$ & $0 \pm 0$ & $0 \pm 0$ & $0 \pm 0$ \\
\hline 1 & $2.32 \pm 0.32$ & $4.12 \pm 0.25$ & $8.55 \pm 0.19$ & $4.23 \pm 0.52$ & $6.13 \pm 0.28$ \\
\hline 2 & $9.43 \pm 0.28$ & $16.87 \pm 0.12$ & $23.65 \pm 0.28$ & $12.64 \pm 0.85$ & $18.54 \pm 0.29$ \\
\hline 4 & $17.43 \pm 0.22$ & $28.76 \pm 0.75$ & $36.65 \pm 0.96$ & $24.87 \pm 0.28$ & $30.32 \pm 0.32$ \\
\hline 6 & $26.54 \pm 0.96$ & $43.67 \pm 0.96$ & $52.43 \pm 0.25$ & $34.65 \pm 0.29$ & $46.43 \pm 0.42$ \\
\hline 8 & $39.32 \pm 0.85$ & $56.87 \pm 0.48$ & $67.23 \pm 0.85$ & $48.45 \pm 0.45$ & $59.22 \pm 0.52$ \\
\hline 10 & $56.23 \pm 0.45$ & $73.22 \pm 0.48$ & $84.54 \pm 0.55$ & $6698 \pm 0.18$ & $76.65 \pm 0.62$ \\
\hline 12 & $70.11 \pm 0.32$ & $85.23 \pm 0.44$ & $91.33 \pm 0.65$ & $83.32 \pm 0.23$ & $93.57 \pm 0.32$ \\
\hline
\end{tabular}

mean \pm SD $(n=3)$

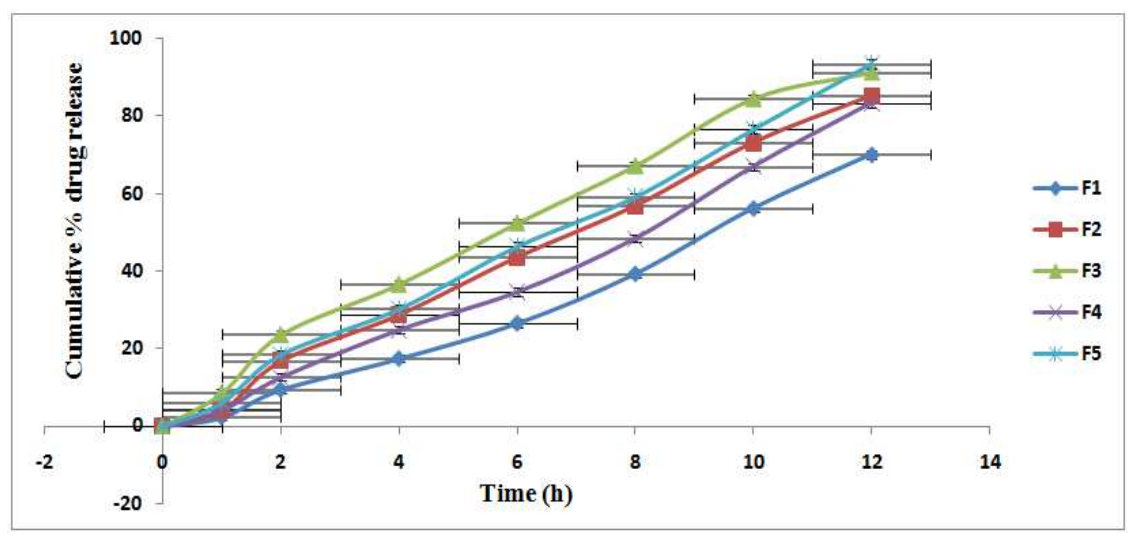

Fig. 2: Drug release profiles of Risperidone formulations F1-F5

Table 5: Cumulative percentage drug release of formulations F6-F10

\begin{tabular}{|c|c|c|c|c|c|}
\hline Time (h) & F6 & F7 & F8 & F9 & F10 \\
\hline 0 & $0 \pm 0$ & $0 \pm 0$ & $0 \pm 0$ & $0 \pm 0$ & $0 \pm 0$ \\
\hline 1 & $5.12 \pm 0.22$ & $6.42 \pm 0.28$ & $13.42 \pm 0.24$ & $7.12 \pm 0.18$ & $7.15 \pm 0.12$ \\
\hline 2 & $10.25 \pm 0.52$ & $21.44 \pm 0.62$ & $22.44 \pm 0.52$ & $16.32 \pm 0.22$ & $22.11 \pm 0.32$ \\
\hline 4 & $20.52 \pm 0.29$ & $31.44 \pm 0.45$ & $32.45 \pm 0.29$ & $26.41 \pm 0.28$ & $31.32 \pm 0.41$ \\
\hline 6 & $32.88 \pm 0.63$ & $44.42 \pm 0.28$ & $47.75 \pm 0.62$ & $38.75 \pm 0.85$ & $47.18 \pm 0.44$ \\
\hline 8 & $45.32 \pm 0.32$ & $59.75 \pm 0.36$ & $68.42 \pm 0.55$ & $50.32 \pm 0.45$ & $61.75 \pm 0.52$ \\
\hline 10 & $59.58 \pm 0.52$ & $73.52 \pm 0.98$ & $81.75 \pm 0.75$ & $66.42 \pm 0.28$ & $75.62 \pm 0.66$ \\
\hline 12 & $78.96 \pm 0.69$ & $84.75 \pm 0.28$ & $96.44 \pm 0.28$ & $83.44 \pm 0.52$ & $90.52 \pm 0.28$ \\
\hline
\end{tabular}

mean \pm SD $(n=3)$ 


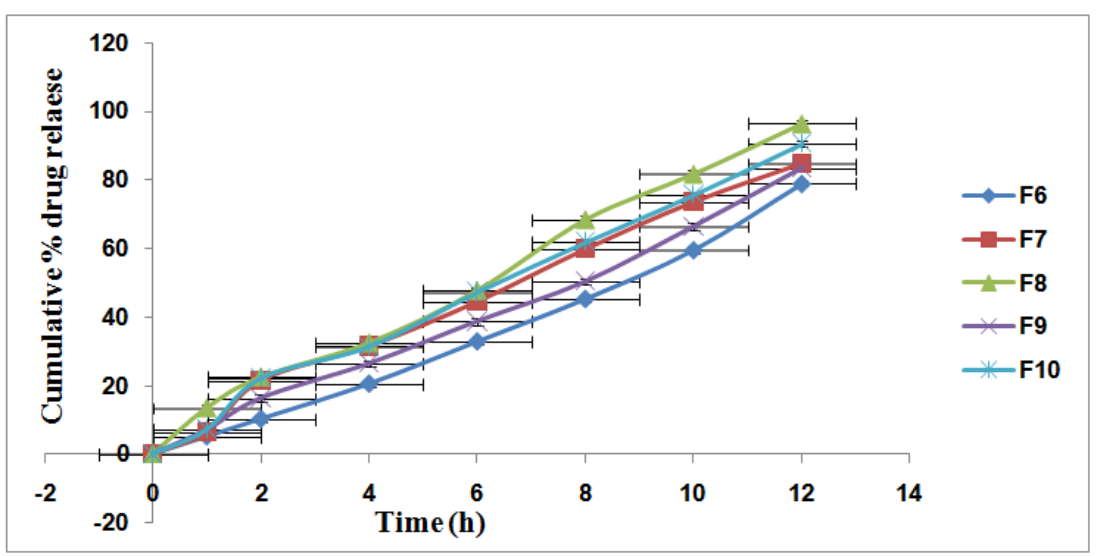

Fig. 3: Cumulative percentage drug release of formulations F6-F10

Table 6: Cumulative percentage drug release of formulations F11-F15

\begin{tabular}{|c|c|c|c|c|c|c|}
\hline Time (h) & F11 & F12 & F13 & F14 & F15 & Innovator \\
\hline 0 & $0 \pm 0$ & $0 \pm 0$ & $0 \pm 0$ & $0 \pm 0$ & $0 \pm 0$ & $0 \pm 0$ \\
\hline 1 & $8.32 \pm 0.85$ & $9.36 \pm 0.62$ & $10.58 \pm 0.32$ & $10.75 \pm 0.75$ & $11.18 \pm 0.42$ & $96.85 \pm 0.52$ \\
\hline 2 & $23.42 \pm 0.32$ & $21.74 \pm 0.35$ & $21.74 \pm 0.86$ & $22.74 \pm 0.85$ & $19.45 \pm 0.33$ & - \\
\hline 4 & $32.45 \pm 0.52$ & $30.85 \pm 0.95$ & $32.65 \pm 0.28$ & $42.75 \pm 0.75$ & $31.74 \pm 0.32$ & - \\
\hline 6 & $48.54 \pm 0.66$ & $46.36 \pm 0.28$ & $45.32 \pm 0.75$ & $57.85 \pm 0.52$ & $47.74 \pm 0.41$ & - \\
\hline 8 & $64.85 \pm .52$ & $59.78 \pm 0.25$ & $58.74 \pm 0.77$ & $75.85 \pm 0.28$ & $62.48 \pm 0.85$ & - \\
\hline 10 & $78.74 \pm 0.75$ & $75.48 \pm 0.85$ & $78.39 \pm 0.96$ & $92.58 \pm 0.74$ & $81.77 \pm 0.18$ & - \\
\hline 12 & $93.62 \pm 0.62$ & $95.52 \pm 0.65$ & $94.85 \pm 0.38$ & $96.51 \pm 0.75$ & $99.45 \pm 0.42$ & - \\
\hline
\end{tabular}

mean \pm SD $(n=3)$

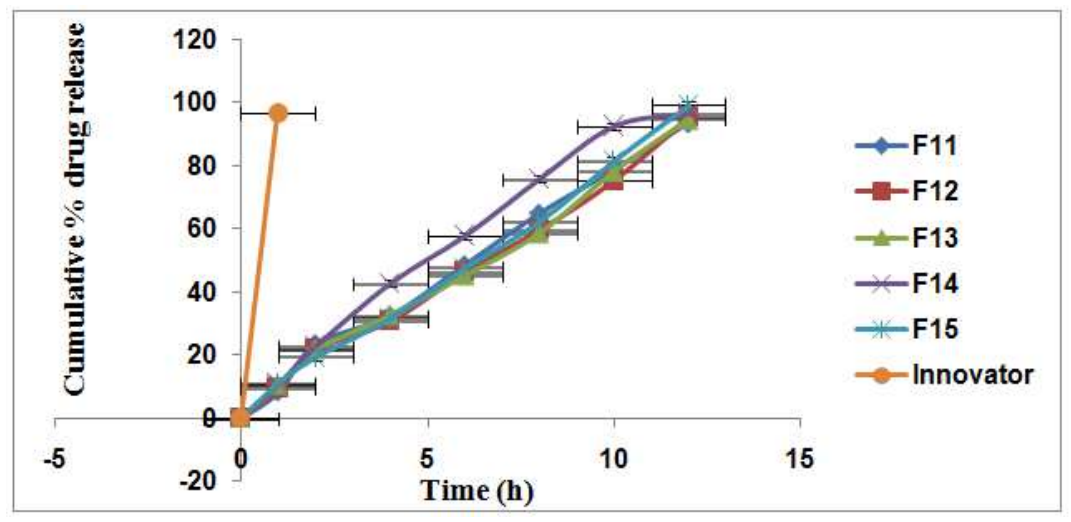

Fig. 4: Cumulative percentage drug release of formulations F11-F15

\section{Mathematical modeling of floating tablets}

To explore the mechanism of drug release from Risperidone floating tablets, various kinetic models like zero order, first order, Higuchi and Korsmeyer-Peppas equations were applied to the different formulations. The release order kinetics of Risperidone optimized formulation (F15) was shown in table 7. From the above results, it is apparent that the regression coefficient value closer to unity in the case of zero-order plot i.e. 0.983 indicates that the drug release follows a zero order mechanism. This data indicates a lesser amount of linearity when plotted by the first order equation. Hence it can be concluded that the major mechanism of drug release follows zero order kinetics. Further, the translation of the data from the dissolution studies suggested the possibility of understanding the mechanism of drug release by configuring the data into various mathematical modeling such as Higuchi and Korsmeyer-Peppas plots. The mass transfer with respect to the square root of time has been plotted, revealed a linear graph with regression value close to one i.e. 0.978 stating that the release from the matrix was through diffusion. Further, the $n$ value obtained from the Korsmeyer-Peppas plots i.e. 0.905 suggest that the drug release from floating tablet was anomalous non-fickian diffusion.

Table 7: Release kinetics of optimized formulation (F15)

\begin{tabular}{lllll}
\hline Formula code & Zero order & First order & Higuchi & Korsemeyer-Peppas \\
\hline F15 & 0.983 & 0.887 & 0.978 & 0.905 \\
\hline
\end{tabular}


Drug-excipient compatibility studies

FT-IR spectrum of Risperidone

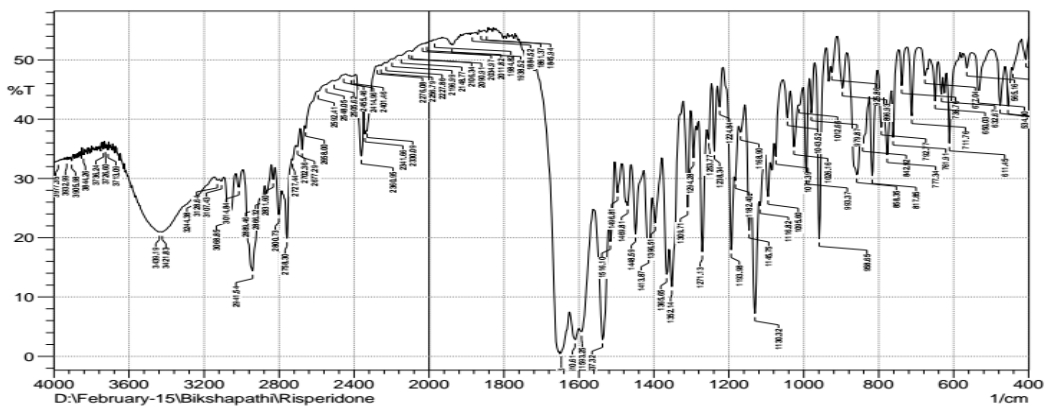

Fig. 5: FTIR spectrum of Risperidone pure drug

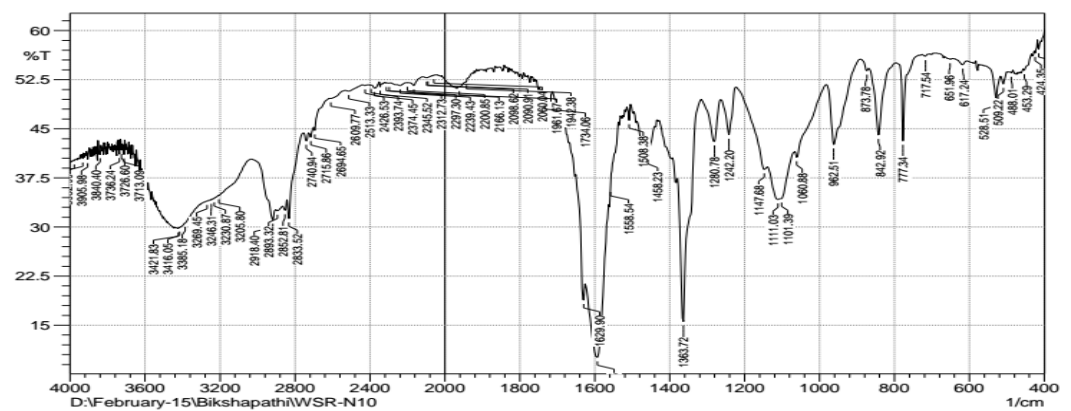

Fig. 6: FT-IR spectrum of drug, HPMC K100 and WSR N10

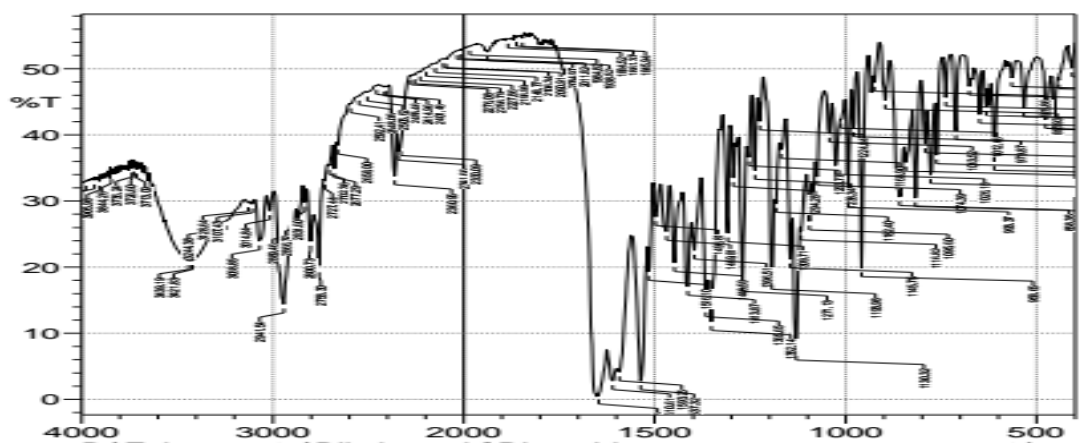

Fig. 7: FTIR spectrum of optimized formulation (F15)

In order to get evidence on the possible interactions of the drug with excipients, FTIR analysis was used. The FTIR spectra of the optimized formulation displayed the characteristic peaks of both drug and polymers. Overall there was no alteration in the characteristic peaks of Risperidone suggesting that there was no interaction between the drug and polymer.

\section{Differential scanning calorimetry (DSC)}

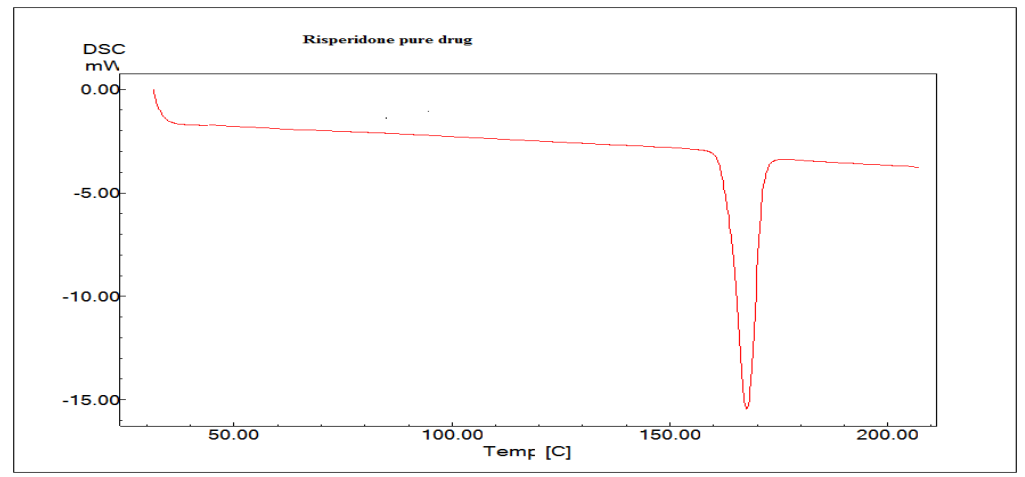

Fig. 8: DSC thermogram of risperidone 


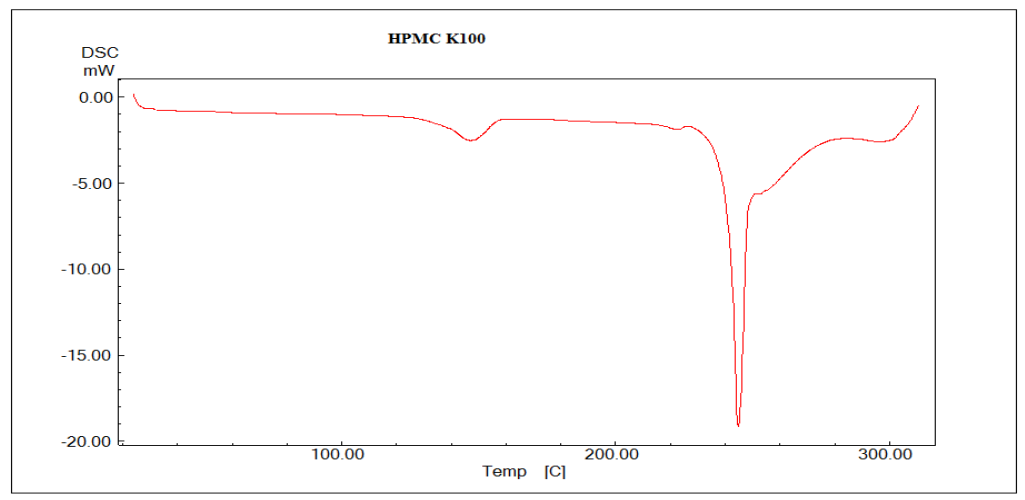

Fig. 9: DSC Thermogram of HPMC K100

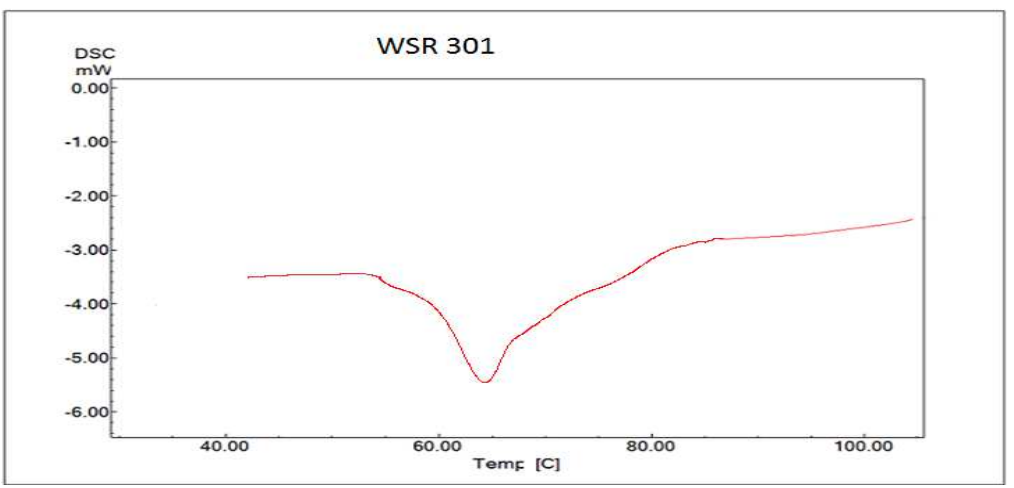

Fig. 10: DSC Thermogram of WSR 301

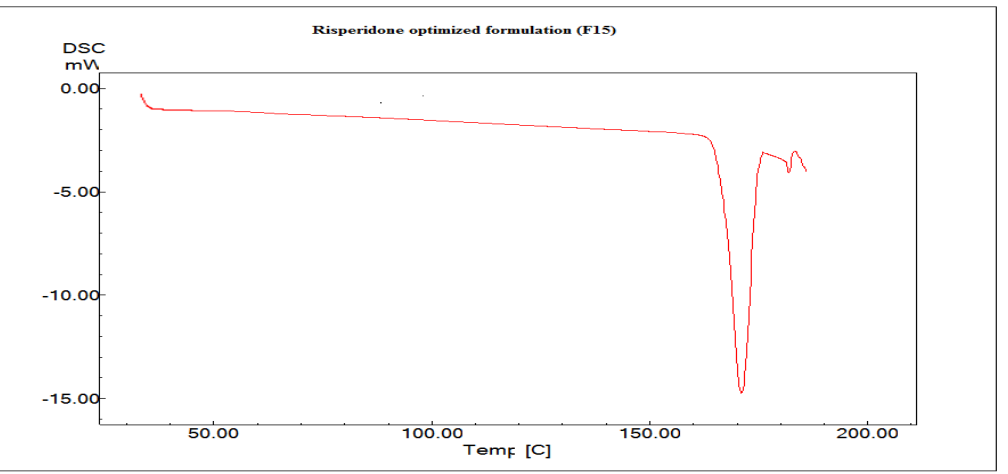

Fig. 11: DSC Thermogram of optimized formulation (F15)

DSC was used to detect interactions between Risperidone and other excipients.

The DSC thermogram of the pure Risperidone (fig. 8) and optimized formulation (F15) (fig. 11) showed endothermic peaks of the pure Risperidone and the Risperidone in the formulation at 170.94 and $171.39{ }^{\circ} \mathrm{C}$ respectively. The endothermic peaks of the HPMC K100 and WSR 301 were also shown in fig. 9 and 10 respectively. It indicates that there is no interaction takes place between drug and other excipients used in the formulation.

\section{Stability studies}

The stability of optimized formulation (F15) of Risperidone floating tablets were tested for stability at $40^{\circ} \mathrm{C} / 75 \% \mathrm{RH}$ in properly closed HDPE bottles along with $1 \mathrm{gm}$ desiccant for 3 mo. The Risperidone release rate (table 8) from the floating tablets (F15) showed no significant change during storage for $3 \mathrm{mo}$; there is no significant change in floating lag time, total floating time and also in vitro drug release profile. The formulation stored in both conditions for $3 \mathrm{mo}$ floated on the surface of the media $(0.1 \mathrm{~N} \mathrm{HCl})$ for $12 \mathrm{~h}$.

Table 8: Physico-chemical characteristics of optimized formulation (F15) stored at $40 \pm 2{ }^{\circ} \mathrm{C} / 75 \pm 5 \% \mathrm{RH}$

\begin{tabular}{llll}
\hline Retest time for F15 & Floating lag time(sec)* & Total floating time (h)* & In vitro drug release profile (\%)* $^{*}$ \\
\hline $0 \mathrm{~d}$ & $30 \pm 2.6$ & $>12 \mathrm{~h}$ & $99.45 \pm 0.12$ \\
$30 \mathrm{~d}$ & $31 \pm 7.4$ & $>12 \mathrm{~h}$ & $98.35 \pm 0.46$ \\
$60 \mathrm{~d}$ & $31 \pm 1.2$ & $>12 \mathrm{~h}$ & $97.61 \pm 0.52$ \\
$90 \mathrm{~d}$ & $33 \pm 3.5$ & $>12 \mathrm{~h}$ & $96.85 \pm 0.22$ \\
\hline
\end{tabular}

*mean $\pm \mathrm{SD}(\mathrm{n}=3)$ 


\section{Intragastric behavior of Risperidone floating tablets}

The radiographic images were taken at different periods post administration of the barium sulfate-loaded tablet in three human volunteers (fig. 12). It is clear that the tablet appears more or less at the same position for the initial $4 \mathrm{~h}$. This could be related to its floating ability. Later on, the tablet was slightly moved downwards, yet remained within the stomach till the end of $6 \mathrm{~h}$. The increased gastric residence time favours an increase in the bioavailability of drugs.

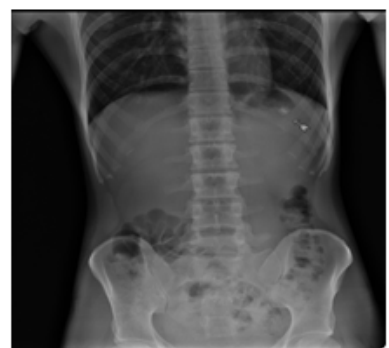

$0.5 h$

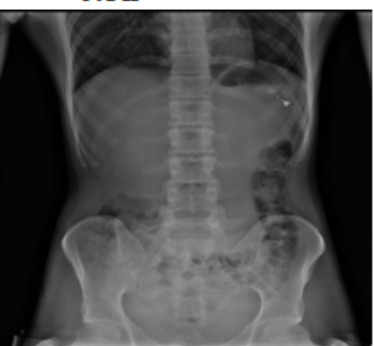

$4 h$

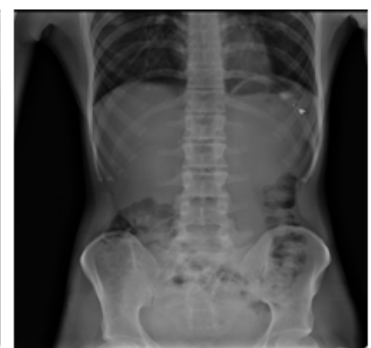

$2 \mathrm{~h}$

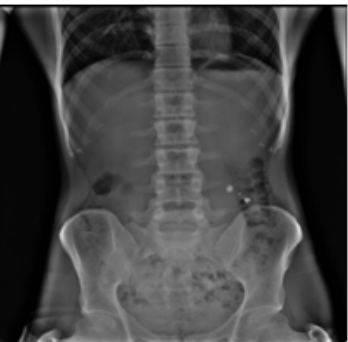

$6 \mathrm{~h}$

Fig. 12: Radiographic images of optimized risperidone floating tablet (F15) in the stomach at different time intervals

In vivo bioavailability studies

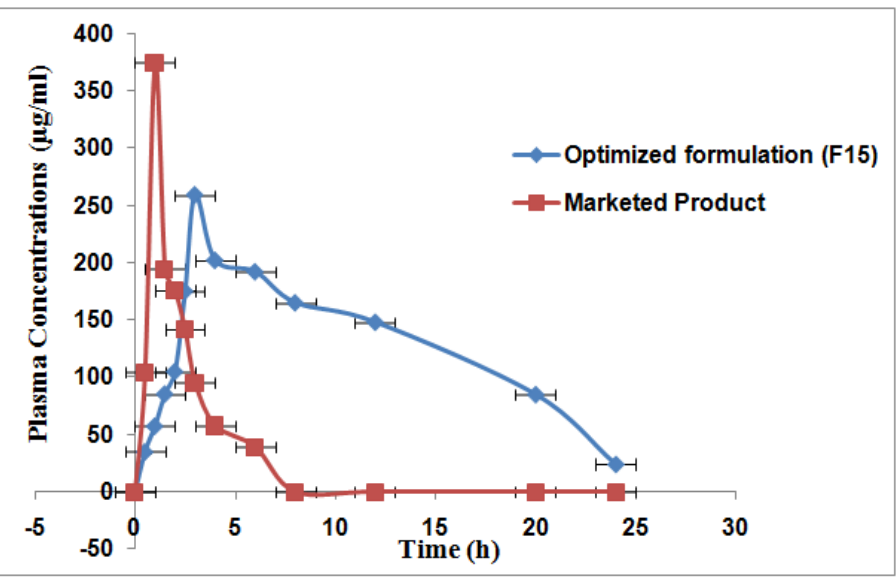

Fig. 13: Plasma concentrations at different time intervals for Risperidone optimized formulation and marketed product

Table 9: Comparison of pharmacokinetic parameters of Risperidone optimized formulation and marketed product

\begin{tabular}{lll}
\hline Parameters & Risperidone optimized formulation & Marketed product \\
\hline $\mathrm{C}_{\max }(\mathrm{ng} / \mathrm{ml})$ & $4.35 \pm 73$ & $5.10 \pm 33$ \\
$\mathrm{AUC}_{0-\mathrm{t}}(\mathrm{ng} . \mathrm{h} / \mathrm{ml})$ & $25.83 \pm 23.14$ & $20.10 \pm 33$ \\
$\mathrm{AUC}_{0-\infty}(\mathrm{ng} . \mathrm{h} / \mathrm{ml})$ & $28.42 \pm 18.24$ & $23.80 \pm 18.12$ \\
$\mathrm{~T}_{\max }(\mathrm{h})$ & $3.50 \pm 1.23$ & $1.50 \pm 0.24$ \\
$\mathrm{t}_{1 / 2}(\mathrm{~h})$ & $8.653 \pm 0.41$ & $3.574 \pm 0.01$ \\
$\mathrm{~K}_{\mathrm{el}}\left(\mathrm{h}^{-1}\right)$ & $0.0833 \pm 0.11$ & $0.342 \pm 0.33$ \\
\hline
\end{tabular}

$n=6 \pm S D$

\section{Bioavailability parameters}

Mean plasma concentration profiles of prepared Risperidone optimized formulation and marketed product are presented in fig. 13. Risperidone optimized formulation exhibited as sustained release in vivo when compared with innovator tablet. All the pharmacokinetics parameters displayed in table 9. In this study in human subjects, prolonged drug absorption was achieved with the test formulation. The average peak concentration of the test formulation was significantly lower than that of the reference $(4.35 \pm 73 \mathrm{ng} / \mathrm{ml}$ for the test formulation versus $5.10 \pm 33 \mathrm{ng} / \mathrm{ml}$ for the reference). In order to estimate the amount of drug absorbed from 
the test formulation, the relative bioavailability was calculated from the AUC of the reference and test formulations $(23.80 \pm 18.12 \mathrm{ng}$. $\mathrm{h} / \mathrm{ml}$ for the reference product versus $28.42 \pm 18.24 \mathrm{ng}$. $\mathrm{h} / \mathrm{ml}$ for the test formulation). The results indicated that the test formulation could increase the bioavailability of Risperidone in humans effectively. In this study, the Risperidone floating tablet produced higher bioavailability than that of a marketed product, this overall increase in bioavailability and increased gastric residence time, caused by flotation of the dosage form in the stomach.

\section{CONCLUSION}

An attempt was made to formulate and evaluate floating drug delivery system containing Risperidone as a model drug, from the data, obtained; it can be concluded that hydrodynamically balanced tablet of an antipsychotic drug Risperidone can be formulated as an approach to increase gastric residence time and thereby improve its bioavailability. Formulation F15 prolonged the release (99.45\% up to $12 \mathrm{~h}$ ) of the drug as compared to other prepared formulations. In vivo radiographic and bioavailability studies performed in healthy human volunteers. From radiographic studies, it is clear that the tablet remained within the stomach till the end of $6 \mathrm{~h} . \mathrm{T}_{\max }, \mathrm{C}_{\max }$, AUC were calculated and confirmed significant improvement in bioavailability when compared with marketed formulation Respidon 2. The data obtained thus suggests that floating delivery system can be successfully designed to give controlled drug delivery, improved oral bioavailability and many other desirable characteristics.

\section{CONFLICTS OF INTERESTS}

\section{Declared none}

\section{REFERENCES}

1. Moes AJ. Gastroretentive dosage forms. Crit Rev Ther Drug Carrier Syst 1993;10:143-95.

2. Chandrashekhar B. floating systems for oral controlled release drug delivery. Int J Appl Pharm 2012;4:1-13.

3. Streubel A, Siepmann J, Bodmeier R. Gastroretentive drug delivery system. Expert Opin Drug Delivery 2006;3:217-33.

4. Rouge N, Allemann E, Gex-Fabry M, Balant L, Cole ET, Buri P, et al. Comparative pharmacokinetic study of a floating multipleunit capsule, a high-density multiple unit capsule and an immediate-release tablet containing $25 \mathrm{mg}$ atenolol. Pharm Acta Helv 1998;73:81-7.

5. Streubel A, Siepmann J, Bodmeier R. Gastroretentive drug delivery system. Expert Opin Drug Delivery 2006;3:217-33.

6. Baumgartner S, Kristi J, Vrecer F, Vodopivec P, Zorko B. Optimization of floating matrix tablets and evaluation of their gastric residence time. Int J Pharm 2000;195:125-35.
7. Iannuccelli V, Coppi G, Bernabei MT, Cameroni R. Air compartment multiple-unit system for prolonged gastric residence. Part I. Formulation study. Int J Pharm 1998;174:47-54.

8. Levina M, Rajabi AR. The influence of excipients on drug release from HPMC. J Pharm Sci 2004;93:2746-54.

9. Bravo SA, Lamas MC, Salomon CJ. Swellable matrices for the controlled release of diclofenac sodium: formulation and in vitro studies. Pharm Dev Technol 2004;9:75-83.

10. Titusville NJ. In: Physician's desk reference Risperdal ${ }^{\circledR}$ Tablets. J Plant Interact 2005;59:662-7.

11. Ascher SH, Faries D, Zhu B, Ernst F, Swartz M. Medication adherence and long-term functional outcomes in the treatment of schizophrenia in usual care. J Chem Phys 2006;67:453.

12. Devis SS. Formulation strategies for absorption windows. Drug Discovery Today 2005;10:249-57.

13. Jaison D, Elango K, Sundar Raj V, Dhunmati K, Kousalya M. Design development and evaluation of trilayer swelling gastro retentive tablets of lornoxicam for biphasic release and lansoprazole for immediate release for the treatment of arthritis. Int J Pharma Res Rev 2015;4:11-21.

14. Romulo Pereira R, Cleverson Gasparetto J, Raquel de Oliveira V. Simultaneous determination of levodopa, carbidopa, entacapone, tolcapone, 3-0-methyldopa and dopamine in human plasma by an HPLC-MS/MS method. Bioanalysis 2015;7:207-20.

15. Nerurkar J, Jun HW, Price JC. Controlled release matrix tablets of ibuprofen using cellulose eather and carragenen; effect of formulation factors on dissolution rates. Eur J Pharm Biopharm 2005;61:56-68.

16. Kavitha K, Puneeth KP, Tamizh Mani T. Development and evaluation of rosiglitazone maleate floating tablets using natural gums. Int J PharmTech Res 2010;2:1662-9.

17. Garg R, Gupta GD. Progress in controlled gastro retentive delivery systems. Trop J Pharm Res 2008;7:1055-66.

18. Prasanna Kumari J, Ramarao T, Jayaveera KN, Bhikshapathi DVRN, Madhusudan Rao Y. Design and in vivo evaluation of metoprolol tartrate bilayer floating tablets in healthy human volunteers. Int J Drug Delivery 2014;6:14-23.

19. Dhara P, Jayvadan P. Development and validation of RP-HPLC method for simultaneous estimation of risperidone and trihexyphenidyl hydrochloride in tablet dosage forms. Int J Pharm Sci Rev Res 2010;4:85-8.

\section{How to cite this article}

- A Kishore Babu, MV Ramana. Development and in vivo evaluation of gastro retentive floating tablets of antipsychotic drug risperidone. Int J Pharm Pharm Sci 2016;8(11):43-52. 